\title{
Left Para-Duodenal Hernia with Intestinal Obstruction by Bridle: A
} Case Report

Soumia Arharas ${ }^{1 *}$, Laurent Hermann Marion Ondima ${ }^{1}$, Badr Boutakioute ${ }^{1}$, Meriem Ouali Idrissi ${ }^{1}$, Najat Cherif Idrissi Ganouni ${ }^{1}$, Fathilah karim Maaroufi $^{2}$, Wafae Ait belaid ${ }^{2}$, Abdelatif Nebgui ${ }^{2}$, Khalid Rabbani ${ }^{2}$, Benasser Finech ${ }^{2}$

${ }^{1}$ Service de Radiologie, Cadi Ayyad University, university hospital Mohammed VI of Marrakech, Morocco

${ }^{2}$ Visceral Surgery Department, Cadi Ayyad University, university hospital Mohammed VI of Marrakech, Morocco

DOI: $\underline{10.36347 / \text { simcr.2021.v09i02.020 }}$

| Received: 27.01.2021 | Accepted: 11.02.2021 | Published: 28.02.2021

*Corresponding author: Soumia Arharas

Abstract

The left para-duodenal hernia or mesocolic hernia is a rare cause of occlusion for young adults, its association with a peritoneal bridle is exceptional. We reporting a case of a 20 -year-old young man with a history of appendectomy presenting with occlusion syndrome. Abdominal CT scan with contrast suggests the diagnosis of left para-duodenal hernia, with intraoperative discovery of a bridle in the right iliac fossa. In view of the non-specific clinical presentation, internal hernias is a challenging diagnostic. Intestinal obstruction by bridles remains the main differential diagnosis, however a possible association should not be overlooked.

Keywords: Left para-duodenal internal hernia, intestinal occlusion by bridles, abdominal CT scan.

Copyright $\left({ }^{\circ} 2021\right.$ The Author(s): This is an open-access article distributed under the terms of the Creative Commons Attribution 4.0 International License (CC BY-NC 4.0) which permits unrestricted use, distribution, and reproduction in any medium for non-commercial use provided the original author and source are credited.

\section{INTRODUCTION}

Internal hernia is a rare condition that results from a viscus protruding through a congenital or acquired intraperitoneal foramen [1]. It is responsible for at least $1 \%$ of abdominal hernias, considered to be a rare cause of intestinal obstruction [2]. The left paraduodenal hernia is the most common (40\% of internal hernias). It constitutes a diagnostic challenge given the non-specificity of the symptoms [3]. We report a clinical case of Intestinal occlusion by a left paraduodenal internal hernia associated with bridle in a 20-year-old patient.

\section{Case Report}

A 20-year-old male patient, he is appendectomy 6 years ago, presented for early food vomiting with inability to pass gas or stool associated with diffuse abdominal pain, evolving since a day, in a state of apyrexia and good general condition. Clinical examination found a diffuse abdominal tenderness on palpation. White blood cell count $11640 / \mathrm{mm} 3$ with normal CRP at $3.7 \mathrm{mg} / \mathrm{L}$, electrolytes test was unremarkable. Abdominal X-ray showed multiple airfluid levels in the small bowel in the left upper quadrant (Figure 1). Abdominal CT scan confirm small bowel obstruction with a sac-like appearance of small bowel loops of jejunum in left upper quadrant between the stomach and pancreas (Figure-2), with stretched and thickened mesenteric vessels converging to a central point and mesenteric whirl sign. Also, note that the remainder of the large bowel is completely collapsed (Figure-3). These findings are suggestive of the diagnosis of left paraduodenal hernia and confirmed by surgery (Figure-4), a huge hernia sac located left to the Treitz ligament was found, it contained a 1.5 meters of viable dilated loops of small bowel associeted with a bridle in the right iliac fossa tie the last ileal loop, which explain the intestinal distension downstream of the hernial pseudo-sac on CT scan. The hernia was reduced and the defect was closed followed by debridement of adhesive band of the right iliac fossa. The patient had good postoperative recovery without complications at routine outpatient follow-up. 


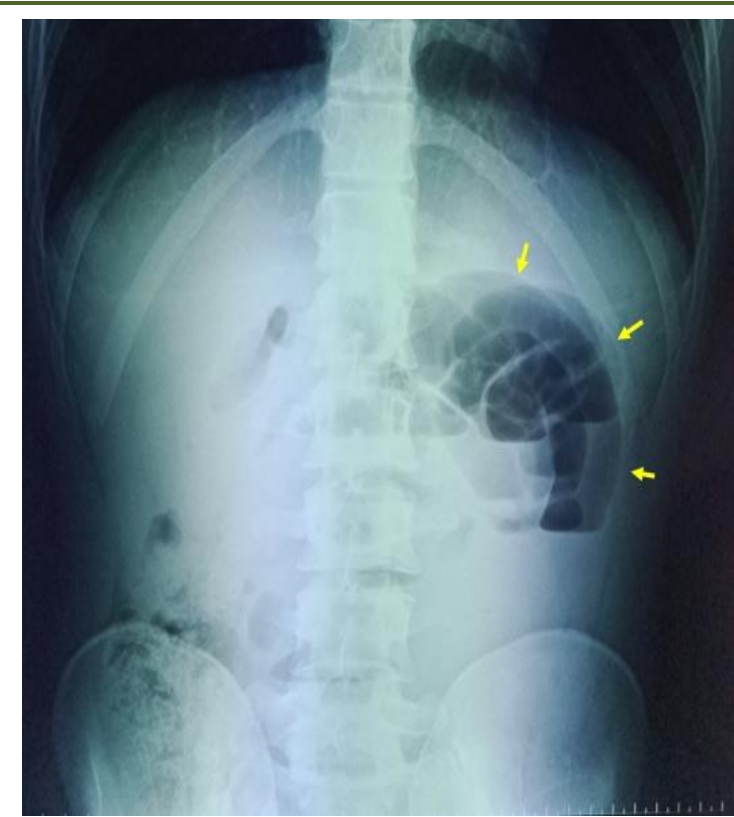

Fig-1: Abdominal X-ray: multiple air-fluid levels higher than wide in the left upper quadrant (yellow arrows)

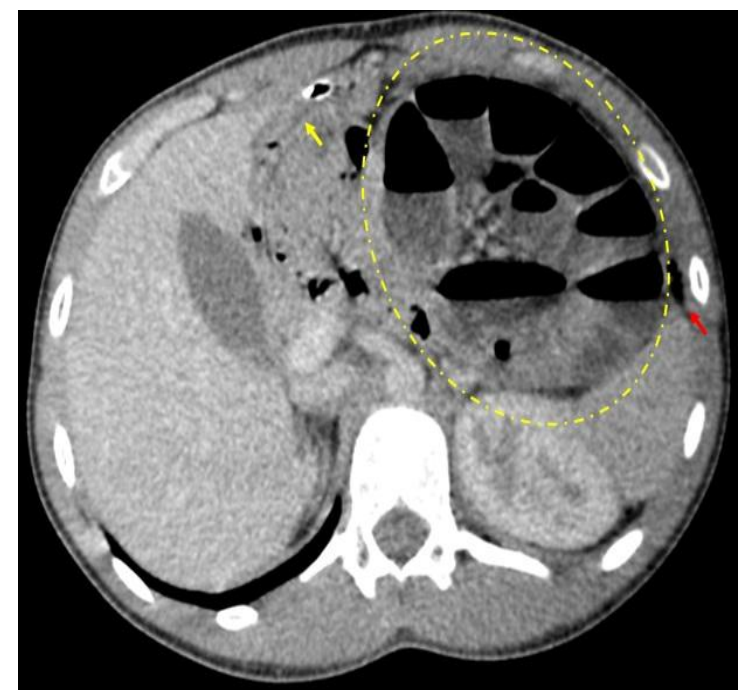

Fig-2: Contrast-enhanced abdominal CT-scan, portal venous phase (axial cut): Shows a sac-like clustered and dilated small bowel loops in the left upper quadrant (yellow circle), pushing back the stomach (yellow arrow) and the transverse colon forward (red arrow)

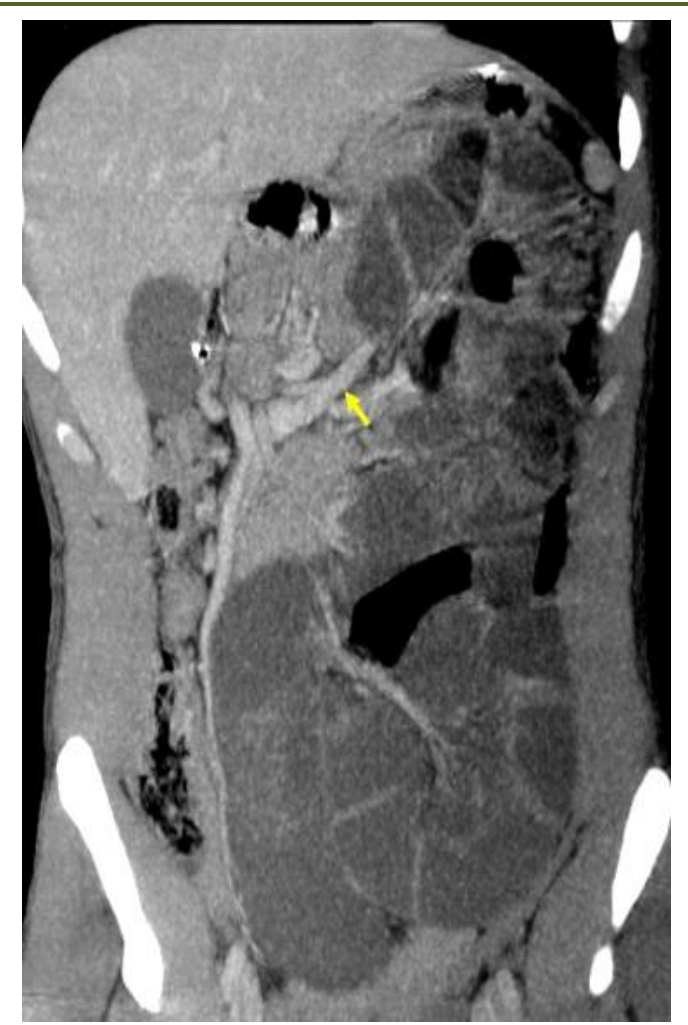

Fig-3: Contrast-enhanced abdominal CT-scan, portal venous phase (coronal cut with MIP): The inferior mesenteric vein constitutes an anatomical landmark which is moved forward and upward (arrow)

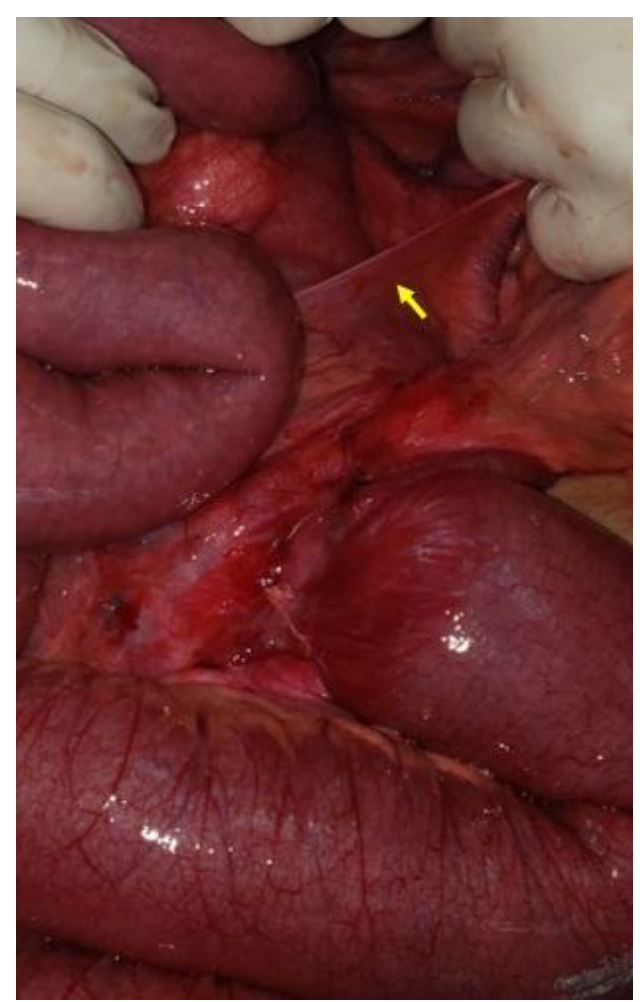

Fig-4: Intraoperative view: Protrusion of the small intestin al loops in the hernial sac

(arrow) 


\section{DISCUSSION}

Internal hernias result from protrusion of the vi scera through a peritoneal or mesenteric orific. They rep resent less than $2 \%$ of intestinal obstruction [4]. Paradu odenal hernias are the most common type of congenital internal hernias (30 to 50\%) with a predominance of left paraduodenal hernias $(75 \%)$ compared to right ones $(25$ $\%)[4,5]$. They interest men three times more than wom en with a mean age of diagnosis of 38.5 years $[6,7]$. Th e left paraduodenal hernia develops in the Landzert foss a, located at the level of the duodeno-jejunal angle in th e left descending and transverse mesocolon [8].

The symptomatology is variable, it manifests e ither by intermittent crises such as abdominal cramps, e pigastric distension, nausea and vomiting; or after a co mplication (strangulation) the signs are those of an acut e small intestinal obstruction [7].

The preoperative diagnosis of internal abdomi nal hernia, including para-duodenal hernia, might be dif ficult due to its non-specific clinical presentation [9]. $\mathrm{H}$ owever, it must be precise due to the potentially serious complications.

The abdominal X-ray is most often not very co ntributory. Small intestine transit makes it possible to o bjectify an intestinal mass encircled in a sac [10]. Curre ntly, contrast-enhanced abdominal computed tomograp hy (CT) imaging is the exam of choice which plays an e ssential role in the diagnostic orientation with a high se nsitivity of 94 to $100 \%$ and a specificity of 90 to $95 \%$ [9 , 5]. It show a cluster of bowel loops with a sac-like in $\mathrm{t}$ he left upper quadrant at the level of the duodenojejunal junction, between the pancreas and the stomach to the le $\mathrm{ft}$ of the Treitz angle $[8,9]$. It can suggest the diagnosis, nevertheless the key anatomic landmark is the deplacem ent of the inferior mesenteric vein and colic artery at the anterior and medial border of the hernia orifice $[5,8]$.

Treatment is based on surgery, traditionally wi th a midline approach compared to the laparoscopic one which remains hazardous in the emergency, in front of a severe intestinal obstruction [10]. Herniated small intest ine is located under a peritoneal layer of the descending mesocolon [10]. Preventive treatment consists of closin $\mathrm{g}$ the hernial orifice using separate stitches of absorbabl e or not absorbable sutures, without excision of the hern ial sac [10].

The differential diagnosis is made with the tran smesenteric internal hernia [8], but mainly with an intes tinal obstruction by bridles before a history of previous abdominal surgery as in the case of our patient. Howeve $r$, the association of these two etiologies is possible, hen ce the interest in looking for the CT signs of obstruction 11 . by bridle in front of the distension of the intestinal loops downstream of the hernial sac.

\section{CONCLUSION}

Left para-duodenal internal hernia is a rare cau se of acute bowel obstruction in adults, its association w ith a peritoneal bridle is possible especialy with history of abdominal surgery. It represents a diagnostic challen ge for the radiologist facilitated by the use of contrast-e nhanced abdominal CT.

Declaration of Interests: The authors declare that they have no conflicts of interest.

\section{REFERENCES}

1. Sleiman Y, El-Kheir A, El-Khoury M, Hamdach O, Ismail L, Allouch M. Small bowel obstruction secondary to left paraduodenal hernia: a case report and literature review. International journal of surgery case reports. 2018;53:29-31.

2. Kadhem S, Ali MH, Al-dera FH, Alzayer NA, Alyagoub HM. Left Paraduodenal Hernia: Case Report of Rare Cause of Recurrent Abdominal Pain. Cureus. 2020;12(3).

3. Jin C, Mo J, Wang G, Jiang H, Feng Y, Wang S. Paraduodenal hernia complicated with intussusception: case report. BMC surgery. 2018;18(1):120.

4. Kozman MA, Fisher OM. Left paraduodenal hernia: a rare complication following laparoscopic appendectomy. Case reports in surgery. 2017.

5. Monica ML, Antonella M, Gloria A, Diletta C, Nicola M, Ginevra D. Internal hernias: a difficult diagnostic challenge. Review of CT signs and clinical findings. Acta Bio Medica: Atenei Parmensis. 2019;90(5):20.

6. John M, Michael H, Matthew S, Anthony U, David D, Pablo G. Identification and Repair of Left-Sided Paraduodenal Hernia Using Both Laparoscopic and Robotic Techniques. Case Reports in Surgery. 2020.

7. Medarhri J, El Ounani M, Rachid K, Jaafar A, Iken A, Echarrab M. Hernie interne paraduodénale gauche à propos d'une nouvelle observation. Journal de chirurgie (Paris. 1908), 1996;133(9-10):462-465.

8. Al Otaibi RS, Al Maghrabi HS, Dous YB, Malaekah H. A Rare Case of Small Bowel Obstruction Due to Paraduodenal Hernia. The American journal of case reports. 2019;20:1581.

9. Mathias J, Phi I, Bruot O, Ganne PA, Laurent V, Régent D. Hernies internes. EMC, 2014.

10. Kotobi H, Echaieb A, Gallot D. Traitement chirurgical des hernies rares. EMC-Chirurgie. 2005;2(4):425-439. 